\title{
Eurolntervention
}

\section{Biolimus-eluting biodegradable polymer versus sirolimus- eluting permanent polymer stent performance in long lesions: results from the LEADERS multicentre trial substudy}

Joanna J. Wykrzykowska1, MD; Lorenz Räber'12, MD: Ton de Vries², MSc; Marco Bressers², PhD; Pawel Buszman ${ }^{3}, \mathrm{MD}$; Axel Linke ${ }^{4}$, MD; Thomas Ischinger ${ }^{5}, \mathrm{MD}$; Volker Klauss ${ }^{6}, \mathrm{MD}$; Franz Eberli ${ }^{7}$, MD; Roberto Corti ${ }^{7}$, MD; William Wijns ${ }^{8}$, MD; Marie-Claude Morice $^{9}$, MD; Carlo di Mario ${ }^{10}$, MD PhD; Evelyn Regar', MD, PhD; Peter Jüni11, MD; Stephan Windecker ${ }^{11,12}$, MD; Patrick W. Serruys', MD, PhD

1. The Department of Interventional Cardiology Thoraxcenter, Erasmus MC, Rotterdam, The Netherlands; 2. Cardialysis B.V., Rotterdam, The Netherlands; 3. Medical University of Silesia, Katowice, Poland; 4. Herzzentrum Leipzig, Leipzig, Germany; 5. Department of Cardiology, Hospital Bogenhausen, Munich, Germany; 6. Department of Cardiology, University Hospital Munich (Innenstadt), Munich, Germany; 7. Department of Cardiology, University Hospital Zurich, Zurich, Switzerland; 8. Department of Cardiology, Onze Lieve Vrouw Ziekenhuis, Aalst, Belgium; 9. Institut Cardiovasculaire, Paris-Sud, France; 10. Department of Cardiology, Royal Brompton Hospital, London, United Kingdom; 11. CTU Bern, Bern University Hospital, Bern, Switzerland; 12. Department of Cardiology, Bern University Hospital, Bern, Switzerland

The study was sponsored by Biosensors, Europe SA, Switzerland. Stephan Windecker is a consultant to Biosensors, Abbott, Boston Scientific, Cordis and Medtronic. The remaining authors have no conflict of interest to declare.

\section{KEYWORDS}

Biolimus-eluting stent (BES), sirolimuseluting stent (SES), biodegradable polymer, target vessel revascularisation, long lesions

\begin{abstract}
Aims: Lesion length remains a predictor of target lesion revascularisation and results of long lesion stenting remain poor. Sirolimus-eluting stents have been shown to perform better than paclitaxel eluting stents in long lesions. In this substudy of the LEADERS trial, we compared the performance of biolimus biodegradable polymer (BES) and sirolimus permanent polymer stents (SES) in long lesions.

Methods and results: A total of 1,707 'all-comer' patients were randomly allocated to treatment with BES and SES. A stratified analysis of angiographic and clinical outcomes at nine months and one year, respectively was performed for vessels with lesion length $<20 \mathrm{~mm}$ versus $>20 \mathrm{~mm}$ (as measured by quantitative angiography). Of 1,707 patients, 592 BES patients with 831 lesions and 619 SES patients with 876 lesions had only short lesions treated. One hundred and fifty-three BES patients with 166 lesions and 151 SES patients with 162 lesions had long lesions. There were no significant differences in baseline clinical characteristics, except for higher number of patients with long lesions presenting with acute myocardial infarction in both stent groups. Long lesions tended to have lower MLD and greater percent diameter stenosis at baseline than short lesions. Late loss was greater for long lesions than short lesions. There was no statistically significant difference in late loss between BES and SES stents $(0.32 \pm 0.69$ vs $0.24 \pm 0.57, p=0.59)$. Binary in-segment restenosis was present in $23.2 \%$ versus $13.1 \%$ of long lesions treated with BES and SES, respectively $(p=0.042)$. In patients with long lesions, the overall MACE rate was similar for BES and SES ( $17 \%$ vs $14.6 \% ; p=0.62)$. There was a trend towards higher overall TLR rate with BES ( $12.4 \%$ vs $6.0 \%$; HR=2.06; $\mathrm{p}=0.07$ ) and clinically driven TLR ( $10.5 \%$ vs $5.3 \%$ : HR $1.94 ; p=0.13)$. Rates of definite stent thrombosis were $3.3 \%$ in the long lesion group and $1.3-1.7 \%$ in the short lesion group.

Conclusions: BES and SES appear similar with respect to MACE in long lesions in this "all-comer" patient population. However, long lesions tended to have a higher rate of binary in-segment restenosis and TLR following BES than SES treatment.
\end{abstract}

* Corresponding author: Interventional Cardiology, Thoraxcenter, Erasmus MC, 's Gravendijkwal 230 Bd 412, 3015CE Rotterdam, The Netherlands E-mail:p.w.j.c.serruys@erasmusmc.nl 


\section{Introduction}

Drug eluting stents have considerably reduced restenosis and the need of repeat revascularisation compared to bare metal stents. ${ }^{1,2}$ The ADVANCE study was the first to demonstrate that stenting in long lesions (> $40 \mathrm{~mm}$ ) was associated with higher MACE rates. ${ }^{3}$ Sirolimus eluting stents (SES) have been shown to yield superior results to paclitaxel eluting stents in most, but not all studies, ${ }^{1,4,5}$ particularly in complex lesions and patient populations. ${ }^{6,7}$ Patients with long lesions remain at increased risk for impaired long-term clinical outcome mainly related to repeat revascularisation procedures. In a study of 500 patients with long lesions, SES showed superior angiographic outcome in terms of late loss (0.09 vs $0.45 \mathrm{~mm} ; \mathrm{p}<0.001$ ), percent diameter stenosis and binary restenosis (3.3\% vs $14.6 \%$; $R R=0.23 ; p<0.001$ ), as well as TLR rates $(2.4 \%$ vs $7.2 \% ; p=0.012)$ but not overall MACE rates. ${ }^{5}$

Biolimus is a highly lipophilic sirolimus analogue. ${ }^{8}$ It inhibits the mammalian target of rapamycin (mTOR) and cell-cycle transition in smooth muscle cells with similar potency to sirolimus. In the LEADERS multicentre randomised study of biolimus-eluting biodegradable polymer stent (BES) versus sirolimus-eluting permanent polymer stent (SES), we noted that late loss in the overall patient population was similar for BES than SES (0.13 versus $0.19 \mathrm{~mm} ; \mathrm{p}=0.34$ at 9 months). ${ }^{9}$ In the present stratified analysis of lesion length, we investigated the outcome of patients with short and long lesions following treatment with BES and SES. We hypothesised that since late loss and TLR rates were non-inferior for the BES in the overall population in LEADERS, that this stent will also perform equivalently to SES in the long lesion subset.

\section{Methods}

\section{Study population}

LEADERS was a multicentre European non-inferiority trial comparing safety and efficacy of BES to SES in 1,707 'all comer' patients. Patients over the age of 18 with chronic stable coronary artery disease or acute coronary syndromes including ST-elevation myocardial infarction were eligible if they had at least one lesion with $>50 \%$ diameter stenosis and reference vessel diameter 2.25 to $3.5 \mathrm{~mm}$. The aim was for the patient population to reflect real clinical practice, and thus no limits were set on the number or complexity of the lesions stented. The only exclusion criteria were: known allergy to acetylsalicylic acid, clopidogrel, heparin, stainless steel, sirolimus, biolimus or contrast material that cannot be pre-medicated, planned surgery within six months of percutaneous coronary intervention - unless the dual antiplatelet therapy could be maintained throughout the peri-surgical period, pregnancy or participation in another trial before reaching the primary end-point and lastly, inability to give informed consent. The study complied with the Declaration of Helsinki and was approved by all institutional ethics committees. All patients provided written, informed consent for participation in the trial.

\section{Randomisation and procedures}

Randomisation was done centrally after diagnostic cardiac catheterisation and before $\mathrm{PCl}$ by use of a telephone allocation service (Limburgia Telefonische Antwoord Service BV, 3068 NP
Rotterdam, The Netherlands). The allocation sequence was computer generated, stratified according to centre, and blocked with block sizes of eight and 16 which varied randomly. Randomisation was performed on a 1:1 basis to treatment with a stent eluting biolimus-A9 with a biodegradable polylactic acid polymer (Biomatrix Flex, Biosensors Inc., Newport Beach, CA, USA) (Figures $1 \mathrm{a}, \mathrm{b}$ and $\mathrm{c}$ ) or a sirolimus-eluting stent with a durable polymer (Cypher SELECT, Cordis, Miami Lakes, FL, USA)
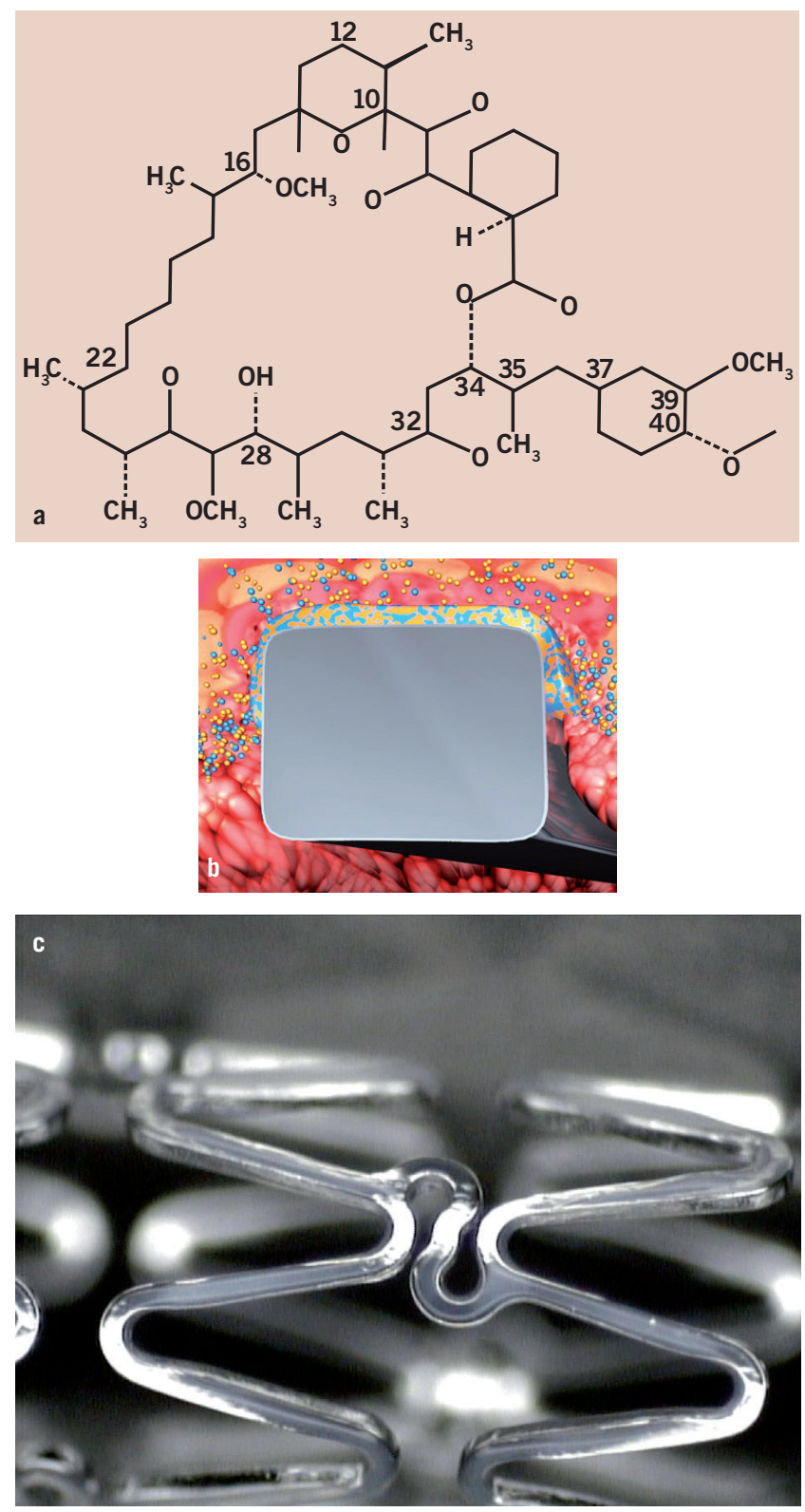

Figure 1. A9тм Eluting Stent: Structure of biolimus and scanning electron micrograph of the biolimus biodegradable polymer stent. 1a. Biolimus is a semi-synthetic sirolimus with 10x higher lipophilicity and similar potency as sirolimus. 1b. Biolimus is immersed at a concentration of $15.6 \mu \mathrm{g} / \mathrm{mm}$ into a biodegradable polymer, polylactic acid and applied solely to the abluminal stent surface by a fully automated process. Polylactic acid is co-released with biolimus and completely dissolves into carbon dioxide and water during a 69 months period. 1c. The stainless steel stent platform has a strut thickness of $112 \mu \mathrm{m}$ with a quadrature link design. 
and to active angiographic follow-up at nine months, or clinical follow-up only on a 1:3 basis with a factorial design.

BES were available in diameters of 2.25, 2.5, 3.0 and $3.5 \mathrm{~mm}$ and in lengths of $8,11,14,18,24$ and $28 \mathrm{~mm}$. SES were available in diameters of 2.25, 2.5, 2.75, 3.0 and $3.5 \mathrm{~mm}$ and in lengths of 8 , 13, 18, 23, 28 and $33 \mathrm{~mm}$. Balloon angioplasty and stent implantation was performed according to standard technique and direct stenting was allowed. No mixture of drug eluting stents was allowed within a given patient, unless the operator was unable to insert the study stent, in which case crossover to another device of the operator's choice was permitted. The length of the stent was left at the discretion of the operators who followed good clinical practice guidelines which include using one stent to cover the lesion when possible. Before, or at the time of the procedure, patients were given at least $75 \mathrm{mg}$ of acetylsalicylic acid, 300-600 mg loading dose of clopidogrel and unfractionated heparin in a dose at least 5,000 IU or 70-100 IU/kg. After the procedure, all patients were advised to take aspirin indefinitely and clopidogrel for at least 12 months. In case of inter-current revascularisation procedures needing stent implantation, treating cardiologists were encouraged to use the study stent. For other details please see the main manuscript. ${ }^{9}$

\section{Study endpoints}

Adverse events were assessed in the hospital and at nine and 12 months. An independent clinical events committee unaware of the patient's treatment assignments adjudicated all endpoints. One in four patients was asked to return for angiographic follow-up at nine months. Definitions of all endpoints are explained in the main manuscript. ${ }^{9}$ Briefly, the pre-specified primary endpoint was the composite of cardiac death, myocardial infarction and clinicallyindicated target vessel revascularisation (TVR) within nine and 12 months. Secondary endpoints were: any target lesion revascularisation (TLR) - both clinically and non-clinically indicated which we defined as repeat revascularisation due to a stenosis within the stent or within a $5 \mathrm{~mm}$ border proximal or distal to the stent; any TVR, cardiac death, death from any cause, myocardial infarction, stent thrombosis (defined according to the ARC) ${ }^{10}$, device success (defined as achievement of a final residual diameter stenosis of less than 50\% during the initial procedure), and lesion success (achievement of less than 50\% stenosis with any approach for $\mathrm{PCl}$ ). The pre-specified principal outcome for angiographic substudy was in-stent percentage diameter stenosis. Secondary angiographic outcomes were: in-segment percentage diameter stenosis, minimal lumen diameter, late lumen loss and binary restenosis. We obtained angiographic measurements within the stented segment (in-stent) and over the entire segment consisting of the stent and $5 \mathrm{~mm}$ proximal and distal margins (in-segment). We defined percentage diameter stenosis as ([reference vessel diameter-minimal luminal diameter]/reference vessel diameter) X $100 \%$; late lumen loss as the difference between minimal lumen diameter after the procedure and minimal lumen diameter at follow-up; and binary restenosis as percentage diameter stenosis of $50 \%$ or greater in the target lesion. Independent study monitors (D-Target, Montagny-pres-Yverdon, Switzerland) verified all case reports from data on-site. Data were stored in a database (KIKA Medical, Paris, France), which was maintained by a contract research organisation (Cardialysis, Rotterdam, The Netherlands) in collaboration with an academic clinical trials unit (CTU Bern, Bern University Hospital, Bern, Switzerland). Clinical follow up was done at 1, 6, 9 and 12 months. The operators were, by necessity, aware of the assigned study stent during $\mathrm{PCl}$ and angiographic follow-up, but patients and staff involved in follow-up assessment were blinded to the allocated stent type. Angiographies were centrally assessed at one angiographic core laboratory (Cardialysis, Rotterdam, The Netherlands) with assessors unaware of the allocated stent.

\section{Statistical analysis}

A stratified analysis of clinical and angiographic outcomes, which was specified after completion of patient recruitment, was performed according to lesion length. Methodology similar to the previously published SIRTAX trial was used. ${ }^{11}$ Patients, who underwent stent implantation in lesions with an lesion length $\leq 20 \mathrm{~mm}$ (as measured by quantitative angiography at index procedure), were categorised as having undergone treatment of short lesion. Conversely, patients who underwent stent implantation in lesions with length $>20 \mathrm{~mm}$ were classified as having had treatment of long lesion. Patients with stent implantations in both short and long lesions were classified as mixed. All randomised patients were included in the analysis of primary and secondary clinical endpoints in the groups that they were originally assigned (intention-to-treat analysis). Analyses of the angiographic substudy were restricted to lesions from patients who attended follow-up angiography. Angiographic outcomes were analysed using SAS v8 Proc Mixed for continuous, and Proc Genmod for binominal outcomes, taking into account the withinpatient correlation structure of these data. We used a Cox proportional hazards model to compare clinical outcomes between the groups. All analyses were performed using SAS 8.02 by a dedicated statistician. All p-values and Cls were two-sided.

\section{Results}

\section{Baseline clinical, angiographic, and procedural data}

Of 1,707 patients, 592 patients in the BES group with 832 lesions and 619 patients in the SES group with 876 lesions had only short lesions treated. One hundred and fifty-three patients in the BES group with 166 lesions and 151 patients with 162 lesions in the SES group had long lesions. (Figure 2) 105 patients with 250 lesions in the biolimus group and 69 patients with 164 lesions in the sirolimus group had both short and long lesions.

Baseline clinical and angiographic characteristics are summarised in Table 1. More patients with long lesions tended to present with ST-elevation MI (26-29\% vs $12 \%$ ) in both stent groups. Patients with long lesions treated with BES tended to have less hypertension (67\% vs $77 \%$ for short lesions, $p=0.027$ ). Patients with long lesions treated with either stent had a greater number of current smokers (29\%-31\% vs 22\%-24\%; p=0.011). Patients with short lesions tended to have been previously treated with percutaneous revascularisation more often, had more strokes and more multivessel disease. 
$\mathrm{N}=2467$ lesions for 1707 patients

Treatment Cypher Select

Treatment Biomatrix III

$\begin{array}{lc}\text { 1213 Lesions for } 850 \text { patients } \\ \text { Lesions } & 1213 \\ \text { Short }(\leq 20 \mathrm{~mm}) & 961 \text { lesions } \\ \text { Long }(>20 \mathrm{~mm}) & 236 \text { lesions } \\ \text { Unknown } & 16 \text { lesions } \\ \text { Patient groups } & 850 \\ \text { Short lesions only } & 619 \\ \text { Long lesions only } & 151 \\ \text { Mixed } & 69 \\ \text { No info available } & 11 \\ \text { Lesions 1213, per patient group: } \\ \text { Short lesions only } & 876 \\ \text { Long lesions only } & 162 \\ \text { Mixed } & 164 \\ \text { No info available } & 11\end{array}$

Figure 2. Flow chart.

Mean lesion length for short lesions was $10.5 \pm 4.4 \mathrm{~mm}$ in the BES group and $10.2 \pm 4.4 \mathrm{~mm}$ in the SES group. Long lesions measured on average $32.6 \pm 14.8 \mathrm{~mm}$ in the BES group and $32.2 \pm 12.5 \mathrm{~mm}$ in the SES group. (Table 1) The distribution for long lesions was skewed to the right with minimum lesion length of $20.03 \mathrm{~mm}$ and maximum lesion length of $101.47 \mathrm{~mm}, 90 \%$ of the long lesions were $20-50 \mathrm{~mm}$. Reference vessel diameters did not differ significantly between lesion or stent types. Long lesions tended to have much lower MLD $(0.48-0.58 \mathrm{~mm}$ vs $1.01-1.05 \mathrm{~mm})$ than short lesions and correspondingly greater percent diameter stenosis (78-82\% vs 59-61\%; $\mathrm{p}<0.001$ ). The lower MLD in the long lesion group was significantly correlated with acute myocardial infarction at presentation (data not shown).

\section{Procedural characteristics and results}

Procedural results are shown in Table 2. Average numbers of stents per lesion were 1.14-1.15 in the short lesions and 1.99-2.0 in the long lesions. Mean stent diameters per lesion were similar between lesion types and groups. Total stent length per lesion was $20 \pm 9 \mathrm{~mm}$ in the short lesions and $43 \pm 22 \mathrm{~mm}$ in the long lesions.

Percent diameter stenosis was $14.1 \pm 8.9 \%$ and $13.9 \pm 7.9 \%$ in the short lesions treated with BES and SES, respectively, $17.2 \pm 7.4 \%$ in the long lesions treated with BES and $17.3 \pm 7.8 \%$ in the long lesions treated with SES. The differences were not statistically significant. Long lesions had significantly greater absolute gain as the lesions treated had lower initial MLDs $(p=0.05)$. This effect was consistent across stent groups.

\section{Angiographic results}

Angiographic follow-up at nine months was obtained in 313 short lesions and 69 long lesions. There was no statistically significant

Table 1. Baseline clinical and angiographic characteristics for short and long lesions.

\begin{tabular}{|c|c|c|c|c|c|c|c|}
\hline & $\begin{array}{c}\text { Biolimus, } \\
\text { short } \\
\text { mean (SD) } \\
\end{array}$ & $\begin{array}{c}\text { Sirolimus, } \\
\text { short } \\
\text { mean (SD) } \\
\end{array}$ & $\begin{array}{c}\text { Biolimus, } \\
\text { long } \\
\text { mean (SD) } \\
\end{array}$ & $\begin{array}{c}\begin{array}{c}\text { Sirolimus, } \\
\text { long } \\
\text { mean (SD) }\end{array} \\
\end{array}$ & $\begin{array}{c}\text { p-value } \\
\text { short vs. } \\
\text { long }\end{array}$ & $\begin{array}{l}\text { p-value short, } \\
\text { Biolimus vs. } \\
\text { Sirolimus } \\
\end{array}$ & $\begin{array}{c}\text { p-value long, } \\
\text { Biolimus vs. } \\
\text { Sirolimus } \\
\end{array}$ \\
\hline \multicolumn{8}{|l|}{ Patient demographics } \\
\hline Number of patients & 592 & 619 & 153 & 151 & & & \\
\hline Age $>65$ & $305(51)$ & $315(51)$ & $71(46)$ & $72(48)$ & 0.19 & 0.83 & 0.82 \\
\hline Male & 433(73) & 458(74) & $122(80)$ & $115(76)$ & 0.12 & 0.74 & 0.45 \\
\hline Diabetes & $156(26)$ & $140(23)$ & $38(25)$ & $36(24)$ & 0.97 & 0.13 & 0.84 \\
\hline Hypertension & $454(77)$ & $458(74)$ & $102(67)$ & 108(71) & 0.027 & 0.28 & 0.36 \\
\hline Hyperlipidaemia & $395(67)$ & $427(69)$ & $89(58)$ & 104(69) & 0.15 & 0.4 & 0.053 \\
\hline Current smoking & $131(22)$ & $147(24)$ & $47(31)$ & $44(29)$ & 0.011 & 0.5 & 0.76 \\
\hline Previous MI & $185(31)$ & $210(34)$ & $47(31)$ & $44(29)$ & 0.37 & 0.32 & 0.76 \\
\hline Previous PCI & $231(39)$ & $257(41)$ & $49(32)$ & $41(27)$ & $<0.001$ & 0.38 & 0.35 \\
\hline Previous stroke & $26(4.4)$ & $17(2.7)$ & $9(5.9)$ & $10(6.6)$ & 0.034 & 0.12 & 0.82 \\
\hline Previous PVD & $44(7.4)$ & 49(7.9) & $13(8.5)$ & $10(6.6)$ & 0.95 & 0.75 & 0.54 \\
\hline Multivessel disease & $123(21)$ & $119(19)$ & $9(6)$ & $8(5)$ & $<0.001$ & 0.5 & 1 \\
\hline \multicolumn{8}{|l|}{ Clinical presentation } \\
\hline Stable angina & $200(34)$ & $218(35)$ & $55(36)$ & $45(30)$ & 0.59 & 0.6 & 0.25 \\
\hline Acute coronary syndromes & $327(55)$ & $332(54)$ & $85(56)$ & $94(62)$ & 0.16 & 0.58 & 0.24 \\
\hline Unstable angina & $142(24)$ & $151(24)$ & $28(18)$ & $19(13)$ & 0.001 & 0.87 & 0.17 \\
\hline STEMI & $76(13)$ & $77(12)$ & $40(26)$ & $43(29)$ & $<0.001$ & 0.83 & 0.65 \\
\hline Non-STEMI & 109(18) & 104(17) & $17(11)$ & $32(21)$ & 0.54 & 0.46 & 0.017 \\
\hline \multicolumn{8}{|l|}{ Angiographic parameters } \\
\hline Number of lesions treated & 831 & 876 & 166 & 162 & & & \\
\hline Lesion length & $10.5 \pm 4.4$ & $10.2 \pm 4.4$ & $32.6 \pm 14.8^{*}$ & $32.2 \pm 12.5^{*}$ & $<0.001$ & 0.41 & 0.98 \\
\hline Reference vessel diameter & $2.62 \pm 0.61$ & $2.61 \pm 0.57$ & $2.60 \pm 0.57$ & $2.64 \pm 0.60$ & 0.83 & 0.75 & 0.44 \\
\hline Minimal luminal diameter & $1.01 \pm 0.44$ & $1.05 \pm 0.46$ & $0.48 \pm 0.51$ & $0.58 \pm 0.57$ & $<0.001$ & 0.08 & 0.25 \\
\hline \%diameter stenosis & $61 \pm 15$ & $59 \pm 15$ & $82 \pm 19$ & $78 \pm 20$ & $<0.001$ & 0.1 & 0.21 \\
\hline
\end{tabular}

* lesion length distribution was skewed to the right and in both stent groups the minimum lesion length was 20.03 and maximum $101.47 \mathrm{~mm}$ with $90 \%$ of lesions falling between 20 and $50 \mathrm{~mm}$ 
Table 2. Procedural outcomes and angiographic follow-up results at nine months for short and long lesions.

\begin{tabular}{|c|c|c|c|c|c|c|}
\hline & $\begin{array}{l}\text { Biolimus, } \\
\text { short }\end{array}$ & $\begin{array}{l}\text { Sirolimus, } \\
\text { short }\end{array}$ & $\begin{array}{l}\text { Biolimus, } \\
\text { long }\end{array}$ & $\begin{array}{l}\text { Sirolimus, } \\
\text { long }\end{array}$ & $\begin{array}{l}\text { p-value BES vs. } \\
\text { SES in the short } \\
\text { lesion groups }\end{array}$ & $\begin{array}{l}\text { p-value BES vs. } \\
\text { SES in the long } \\
\text { lesion groups }\end{array}$ \\
\hline \multicolumn{7}{|l|}{ In-stent } \\
\hline \multicolumn{7}{|l|}{ Reference vessel diameter } \\
\hline Post-procedure & $2.78(0.54)$ & $2.76(0.49)$ & $2.74(0.51)$ & $2.73(0.53)$ & 0.46 & 0.8 \\
\hline *9 month follow-up & $2.84(0.50)$ & $2.78(0.53)$ & $2.79(0.47)$ & $2.61(0.49)$ & 0.34 & 0.18 \\
\hline \multicolumn{7}{|l|}{ MLD } \\
\hline Post-procedure & $2.38(0.50)$ & $2.37(0.46)$ & $2.26(0.45)$ & $2.24(0.43)$ & 0.71 & 0.74 \\
\hline *9 month follow-up & $2.33(0.61)$ & $2.18(0.69)$ & $1.89(0.88)$ & $1.86(0.68)$ & 0.07 & 0.91 \\
\hline Acute gain & $1.37(0.51)$ & $1.33(0.48)$ & $1.80(0.64)$ & $1.66(0.64)$ & 0.1 & 0.03 \\
\hline Late loss & $0.11(0.44)$ & $0.18(0.49)$ & $0.32(0.69)$ & $0.24(0.57)$ & 0.37 & 0.59 \\
\hline \multicolumn{7}{|l|}{$\% D S$} \\
\hline Post-procedure & $14.1(8.9)$ & $13.9(7.9)$ & $17.2(7.4)$ & $17.3(7.8)$ & 0.66 & 0.88 \\
\hline *9 month follow-up & $18.3(15.1)$ & $21.7(18.9)$ & $32.5(28.7)$ & $28.8(21.9)$ & 0.19 & 0.48 \\
\hline Binary restenosis rate $(\%)$ & 3.5 & 8.2 & 16.7 & 10.4 & 0.08 & 0.12 \\
\hline \multicolumn{7}{|l|}{ In-segment } \\
\hline \multicolumn{7}{|l|}{ Reference vessel diameter } \\
\hline Post-procedure & $2.69(0.54)$ & $2.68(0.52)$ & $2.64(0.56)$ & $2.63(0.58)$ & 0.61 & 0.9 \\
\hline *9 month follow-up & $2.79(0.51)$ & $2.70(0.55)$ & $2.73(0.47)$ & $2.56(0.50)$ & 0.17 & 0.25 \\
\hline \multicolumn{7}{|l|}{ MLD } \\
\hline Post-procedure & $2.07(0.52)$ & $2.09(0.50)$ & $2.03(0.49)$ & $1.98(0.48)$ & 0.4 & 0.38 \\
\hline *9 month follow-up & $2.09(0.56)$ & $1.93(0.62)$ & $1.73(0.84)$ & $1.67(0.65)$ & 0.051 & 0.7 \\
\hline Acute gain & $1.05(0.53)$ & $1.04(0.51)$ & $1.56(0.66)$ & $1.40(0.65)$ & 0.73 & 0.013 \\
\hline Late loss & $0.06(0.44)$ & $0.15(0.43)$ & $0.27(0.62)$ & $0.22(0.56)$ & 0.14 & 0.64 \\
\hline \multicolumn{7}{|l|}{$\% D S$} \\
\hline Post-procedure & $22.9(10.3)$ & $21.9(9.8)$ & $23.1(8.6)$ & $24.8(8.7)$ & 0.019 & 0.12 \\
\hline *9 month follow-up & $25.2(14.1)$ & $28.5(18.1)$ & $36.5(28.4)$ & $35.0(20.4)$ & 0.31 & 0.57 \\
\hline Binary restenosis rate $(\%)$ & 4.2 & 10.6 & 23.2 & 13.1 & 0.036 & 0.042 \\
\hline
\end{tabular}

* 9 months angiographic follow-up was done in 69 patients with long lesions (30 treated with BES and 39 treated with SES)

difference in late loss, minimal luminal diameter, percent diameter stenosis or binary restenosis in small or large vessels between BES and SES groups, although this could have been due to the relatively low number of lesions, particularly in the long lesion subgroup (Table 2). Late loss increased more with lesion length in the case of BES stents that in the case of SES stents (Figure 4). Corresponding MLDs and percent diameter stenoses were not significantly different (Table 2). Binary in-stent restenosis was present in 3.5\% versus $8.2 \%$ of short lesions treated with BES and SES respectively, and in $16.7 \%$ versus $10.3 \%$ of long lesions treated with BES and SES $(p=0.12)$. A similar pattern was observed for in-segment restenosis ( $23.2 \%$ vs $13.1 \%$ for long lesions; $p=0.042$ ). The proportion of patients and lesions treated with overlapping stents in long lesions did not differ between BES and SES.

\section{Clinical outcomes}

Clinical events at one year follow-up, stratified by lesion length, are listed in Table 3 and summarised in Figures 3a and 3b as Kaplan Meier curves. There were no significant differences in the rate of MACE through stent groups or lesion types. The overall rates of MACE were: $8.4 \%$ versus $10.2 \%$ in the short lesions treated with BES and SES, respectively ( $p=0.32)$. In patients with long lesions, MACE rate was $17 \%$ vs $14.6 \%$ in the BES and SES groups $(p=0.62)$.
TVR rates were $6.9 \%$ versus $9.9 \%$ in the short lesions in favour of BES ( $p=0.07$ ), $14.4 \%$ versus $7.3 \%$ in the long lesions in favour of SES ( $H R=1.98 ; p=0.07)$. TLR rates shown in Kaplan Meier curves demonstrated similar pattern of SES tending to perform better in long lesions. In addition, TLR increased proportionally to the stent length (divided by tertiles). For stent length of less than $12.9 \mathrm{~mm}$, TLR rate was 4.1\%, for stent length 12.9-19.5 mm 5.6\% and for stent length $>19.5 \mathrm{~mm}$, TLR was $7.4 \%(p=0.0334)$.

The rates of definite stent thrombosis in the long lesion group were $3.3 \%$ in the long lesion group versus $1.3-1.7 \%$ in the short lesion group. For the long lesions group total stent thrombosis rates were $0.7 \%$ for acute, $3.0 \%$ for subacute and $1.3 \%$ for late stent thrombosis (at one year). These rates were comparable for short lesions in acute and late stent thrombosis rates. The rate of subacute stent thrombosis for short lesions was $0.8 \%$ (versus $3.0 \%$ for long lesions).

\section{Discussion}

We present here a novel stent technology now commercially available in Europe, which combines the biodegradable polymer technology with solely abluminal elution of biolimus. Use of drug eluting stents has improved outcomes in patients with coronary artery disease treated with $\mathrm{PCl},{ }^{12}$ including complex lesions. ${ }^{13,14}$ However, lesion length has remained a strong predictor of in-stent 


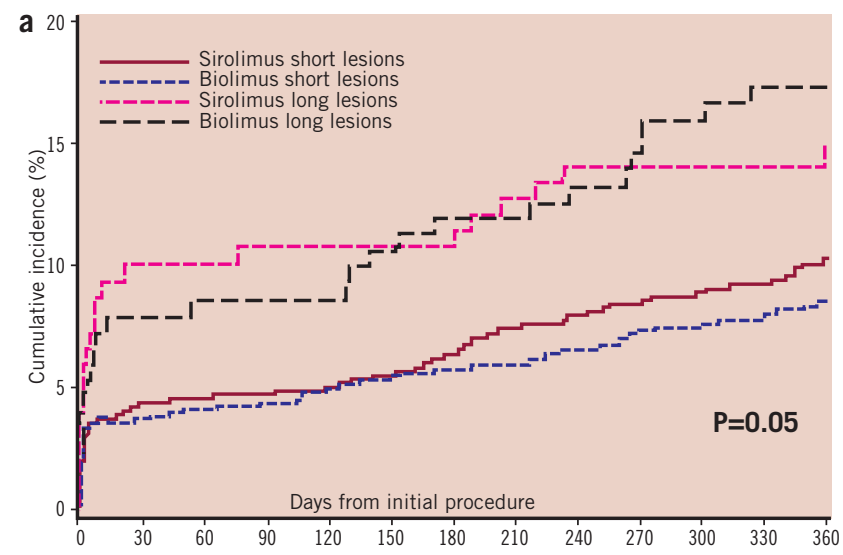

Figure 3a. Kaplan Meier curves for MACE rate at one year follow-up.

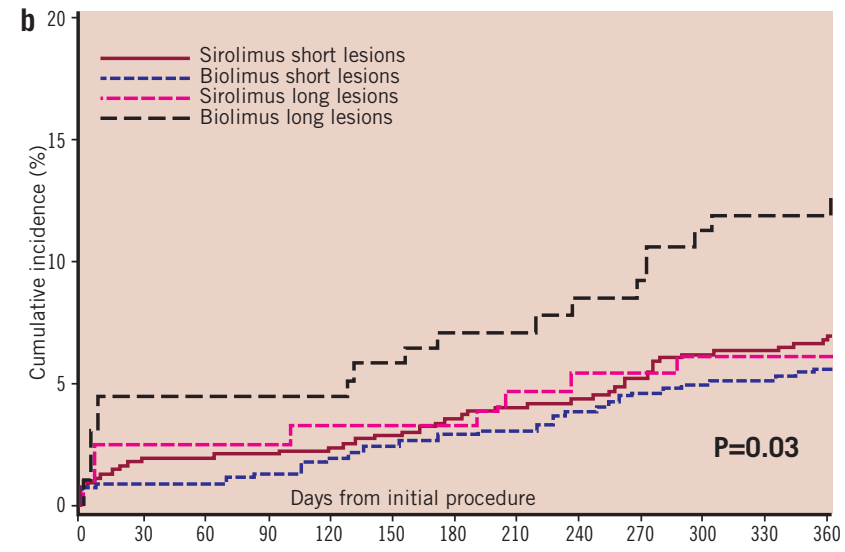

3b. Kaplan Meier curves for TLR rates at one year follow-up.

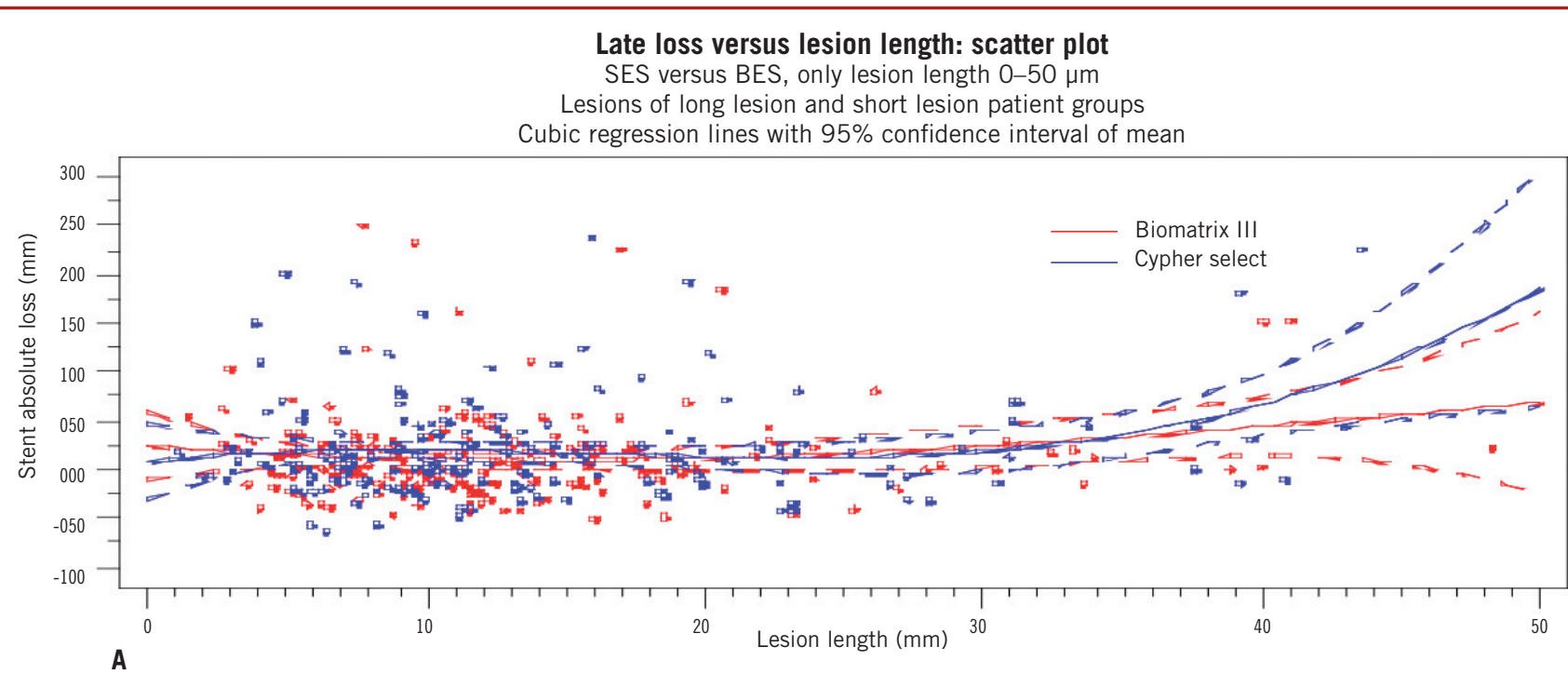

Late loss versus stent length: scatter plot

SES versus BES: only stent length $0-50 \mu \mathrm{m}$

Lesions of long lesion and short lesion patient groups

Cubic regression line with 95\% confidence interval of mean

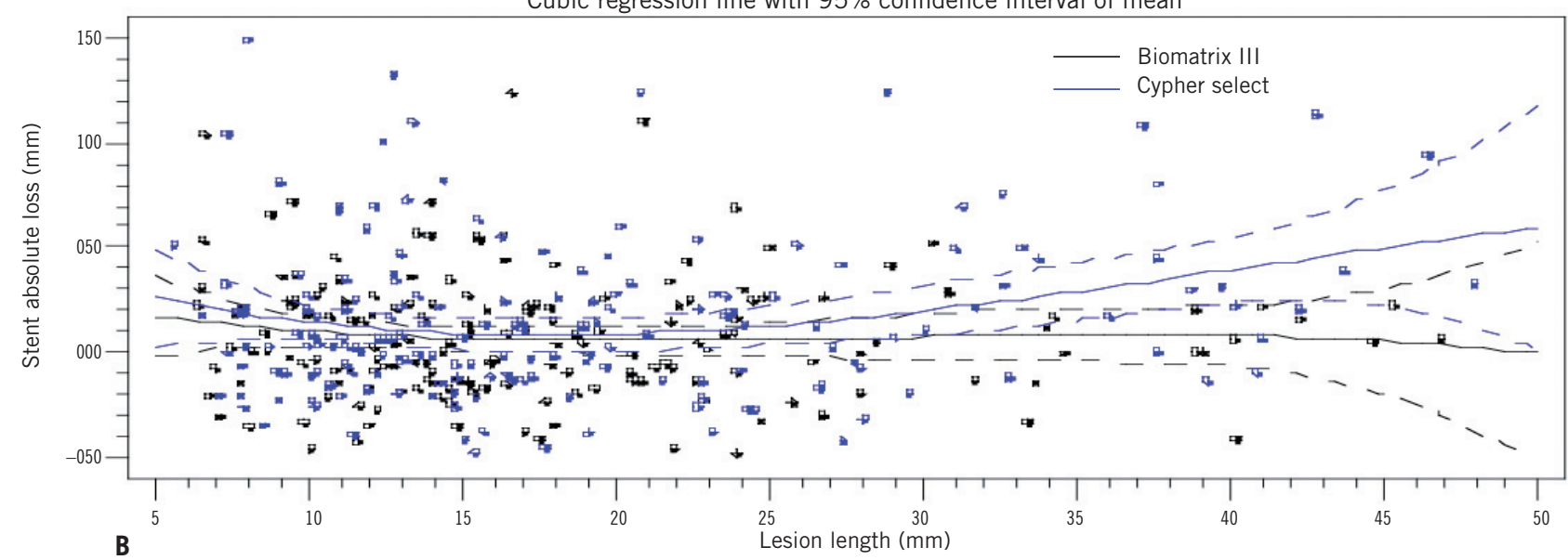

Figure 4. Late loss versus, A) lesion length and B) stent length for BES versus SES.

restenosis. ${ }^{15,16}$ Although the pattern of restenosis after drug eluting stents is more focal rather than diffuse, as with bare metal stents, and therefore more easily treated, it still remains increased for long lesions. 5,7 Paclitaxel eluting stents have been shown to be inferior to sirolimus eluting stents with TVR rates of $7.6 \%$ versus $3.2 \%$
( $p=0.03$ ) in recent studies involving long lesions. ${ }^{5}$ Our study is the first to compare the performance of a biolimus biodegradable polymer stent (BES) with a sirolimus permanent polymer stent (SES) in long lesions. The population studied was an 'all comers' population within the LEADERS trial, with a considerable number of 
Table 3. Clinical outcomes of the short and long lesions stratified with stent type.

\begin{tabular}{|c|c|c|c|c|c|c|c|c|}
\hline & $\begin{array}{c}\text { Biolimus, } \\
\text { short } \\
(n=592)\end{array}$ & $\begin{array}{c}\text { Sirolimus, } \\
\text { short } \\
(n=619)\end{array}$ & $\begin{array}{c}\text { Hazard ratio } \\
\text { (95\% confidence } \\
\text { interval) }\end{array}$ & p-value & $\begin{array}{c}\text { Biolimus, } \\
\text { long } \\
(n=153)\end{array}$ & $\begin{array}{c}\text { Sirolimus, } \\
\text { long } \\
(n=151)\end{array}$ & $\begin{array}{c}\text { Hazard ratio } \\
\text { (95\% confidence } \\
\text { interval) }\end{array}$ & $\mathrm{p}$-value \\
\hline Death & $15(2.5)$ & $12(1.9)$ & $1.31(0.62-2.81)$ & 0.48 & $7(4.6)$ & $10(6.6)$ & $0.67(0.26-1.77)$ & 0.42 \\
\hline Cardiac death & $9(1.5)$ & $9(1.5)$ & $1.05(0.42-2.65)$ & 0.91 & $5(3.3)$ & $9(6.0)$ & $0.53(0.18-1.59)$ & 0.26 \\
\hline MI & $26(4.4)$ & $23(3.7)$ & $1.19(0.68-2.08)$ & 0.55 & $14(9.2)$ & $10(6.6)$ & $1.36(0.60-3.06)$ & 0.46 \\
\hline All TLR & $34(5.7)$ & $44(7.1)$ & $0.81(0.52-1.26)$ & 0.35 & $19(12.4)$ & $9(6.0)$ & $2.06(0.93-4.56)$ & 0.07 \\
\hline TLR percutaneous & $32(5.4)$ & $41(6.6)$ & $0.82(0.52-1.30)$ & 0.4 & $17(11.1)$ & $9(6.0)$ & $1.85(0.82-4.14)$ & 0.14 \\
\hline TLR surgical & $6(1.0)$ & $7(1.1)$ & $0.9(0.30-2.67)$ & 0.85 & $2(1.3)$ & $0(0.0)$ & $>100\left(0-^{*}\right)$ & 1 \\
\hline Clinically justified TLR & $26(4.4)$ & $34(5.5)$ & $0.8(0.48-1.33)$ & 0.39 & $16(10.5)$ & $8(5.3)$ & $1.94(0.83-4.52)$ & 0.13 \\
\hline Clinically justified TLR percutaneous & $25(4.2)$ & $32(5.2)$ & $0.82(0.49-1.38)$ & 0.46 & $15(9.8)$ & $8(5.3)$ & $1.81(0.77-4.28)$ & 0.17 \\
\hline Clinically justified TLR surgical & $4(0.7)$ & $4(0.6)$ & $1.05(0.26-4.20)$ & 0.95 & $1(0.7)$ & $0(0.0)$ & $>100\left(0-^{*}\right)$ & 1 \\
\hline All TVR & $41(6.9)$ & $61(9.9)$ & $0.7(0.47-1.03)$ & 0.07 & $22(14.4)$ & $11(7.3)$ & $1.98(0.96-4.07)$ & 0.07 \\
\hline TVR percutaneous & $37(6.3)$ & $53(8.6)$ & $0.73(0.48-1.11)$ & 0.14 & $19(12.4)$ & $11(7.3)$ & $1.7(0.81-3.56)$ & 0.16 \\
\hline TVR surgical & $8(1.4)$ & $12(1.9)$ & $0.7(0.28-1.70)$ & 0.43 & $3(2.0)$ & $0(0.0)$ & $>100\left(0-^{*}\right)$ & 1 \\
\hline Clinically justified TVR & $29(4.9)$ & $42(6.8)$ & $0.72(0.45-1.15)$ & 0.17 & $18(11.8)$ & $9(6.0)$ & $1.95(0.88-4.34)$ & 0.1 \\
\hline Clinically justified TVR percutaneous & $28(4.7)$ & $39(6.3)$ & $0.75(0.46-1.22)$ & 0.25 & $16(10.5)$ & $9(6.0)$ & $1.72(0.76-3.90)$ & 0.19 \\
\hline Clinically justified TVR surgical & $4(0.7)$ & $6(1.0)$ & $0.7(0.20-2.47)$ & 0.58 & $2(1.3)$ & $0(0.0)$ & $>100\left(0-{ }^{*}\right)$ & 1 \\
\hline Stent thrombosis & $18(3.0)$ & $12(1.9)$ & $1.58(0.76-3.28)$ & 0.22 & $7(4.6)$ & $8(5.3)$ & $0.84(0.31-2.33)$ & 0.74 \\
\hline Definite stent thrombosis & $10(1.7)$ & $8(1.3)$ & $1.31(0.52-3.32)$ & 0.57 & $5(3.3)$ & $5(3.3)$ & $0.97(0.28-3.34)$ & 0.96 \\
\hline Possible stent thrombosis & $5(0.8)$ & $5(0.8)$ & $1.05(0.31-3.64)$ & 0.93 & $1(0.7)$ & $2(1.3)$ & $0.48(0.04-5.27)$ & 0.55 \\
\hline Probable stent thrombosis & $4(0.7)$ & $0(0.0)$ & $>100\left(0-^{*}\right)$ & 0.99 & $1(0.7)$ & $2(1.3)$ & $0.48(0.04-5.31)$ & 0.55 \\
\hline MACE & $50(8.4)$ & $63(10.2)$ & $0.83(0.57-1.20)$ & 0.32 & $26(17.0)$ & $22(14.6)$ & $1.15(0.65-2.04)$ & 0.62 \\
\hline Target vessel failure & $58(9.8)$ & $75(12.1)$ & $0.8(0.57-1.13)$ & 0.21 & $26(17.0)$ & $21(13.9)$ & $1.22(0.69-2.17)$ & 0.5 \\
\hline
\end{tabular}

Values are $n(\%)$, otherwise stated; *Upper limit not defined

high risk lesions, average lesion length in the long lesion group of $32 \mathrm{~mm}$ and high proportion of ST elevation myocardial infarctions (28\% in the long lesion group). The TVR rate in the long lesions was $14.4 \%$ in the BES group and $7.3 \%$ in the SES group with a hazard ratio of 1.98 and a trend towards statistical significance. This is compared to $6.9 \%$ and $9.9 \%$ TVR rates in short lesions, in BES and SES groups respectively. Therefore, SES tended to perform better than BES in long lesions, although the result did not reach statistical significance. Interestingly, in patients with multivessel disease and mixed lesions, the reverse was observed with statistically significant difference in favour of $\mathrm{BES}$ (2.9\% versus $14.5 \%, \mathrm{HR}=0.18$; $\mathrm{p}<0.001$; data not shown). This latter effect did not appear to be explainable by the interaction of stent type with patient diabetic status. In addition, it paralleled the results (presented elsewhere) of stenting by reference vessel diameter, where patients with mixed, small and large diameter reference vessel lesions derived benefit from stenting with BES.

No differences were observed between BES and SES in the rate of MACE, or rate of stent thrombosis in the long lesions although the incidence was rather high in this subgroup.

The angiographic follow-up was limited to one quarter of the patients, and although corresponding differences in late loss and percent diameter stenosis were found between BES and SES stented lesions in the long lesion group, given low patient and lesion numbers the results did not reach statistical significance. Further validation of the results will be needed in larger registries of equally complex patients.

\section{Limitations}

This substudy is limited by post hoc nature of the analysis, and limited number of long-lesions with angiographic follow-up. The study may be under-powered to detect differences in the angiographic outcomes. Longer term follow-up will be necessary to fully assess the performance of biolimus stent, especially with respect to stent thrombosis, since polymer fully degrades at six months.

\section{Conclusions}

Biolimus and sirolimus eluting stents appear equivalent with respect to MACE rate in long lesions in this "all-comer" patient population, however, biolimus treated long-lesion group appears to have higher TLR rates. There were no statistically significant differences in the late loss, percent diameter stenosis or binary restenosis rates for short of long lesions treated with either stent, although the study may have been underpowered to detect these differences in angiographic outcomes.

\section{Acknowledgements}

We would like to thank Dr. Pedro Eerdmans, MD, PhD for his assistance with manuscript preparation and data analysis.

\section{References}

1. Morice MC, Colombo A, Meier B, Serruys P, Tamburino C, Guagliumi G, Sousa E, Stoll HP; REALITY Trial Investigators. Sirolimus- vs paclitaxel-eluting stents in de novo coronary artery lesions: the REALITY trial: a randomized controlled trial. Jama 2006;295(8):895-904. 
2. Morice MC, Serruys PW, Sousa JE, Fajadet J, Ban Hayashi E, Perin M, Colombo A, Schuler G, Barragan P, Guagliumi G, Molnàr F, Falotico R; RAVEL Study Group. A randomized comparison of a sirolimus-eluting stent with a standard stent for coronary revascularization. N Engl J Med 2002;346(23):1773-80.

3. Serruys PW, Foley DP, Suttorp MJ, Rensing BJ, Suryapranata $H$, Materne $P$, van den Bos A, Benit E, Anzuini A, Rutsch W, Legrand V, Dawkins K, Cobaugh M, Bressers M, Backx B, Wijns W, Colombo A. A randomized comparison of the value of additional stenting after optimal balloon angioplasty for long coronary lesions: final results of the additional value of NIR stents for treatment of long coronary lesions (ADVANCE) study. J Am Coll Cardiol 2002;39(3):393-9.

4. Kastrati A, Mehilli J, von Beckerath N, Dibra A, Hausleiter J, Pache J, Schühlen $H$, Schmitt $C$, Dirschinger J, Schömig A; ISAR-DESIRE Study Investigators. Sirolimus-eluting stent or paclitaxel-eluting stent vs balloon angioplasty for prevention of recurrences in patients with coronary in-stent restenosis: a randomized controlled trial. Jama 2005;293(2):165-71.

5. Kim YH, Park SW, Lee CW, Hong MK, Gwon HC, Jang Y, Lee MM, Koo BK, Oh DJ, Seung KB, Tahk SJ, Yoon J, Park SJ. Comparison of sirolimus-eluting stent, paclitaxel-eluting stent, and bare metal stent in the treatment of long coronary lesions. Catheter Cardiovasc Interv 2006;67(2):181-7.

6. Jang JS, Hong MK, Lee CW, Park DW, Lee BK, Kim YH, Han KH, Kim JJ, Park SW, Park SJ. Comparison between sirolimus- and paclitaxeleluting stents for the treatment of chronic total occlusions. J Invasive Cardiol 2006; 18(5):205-8.

7. Degertekin M, Arampatzis CA, Lemos PA, Saia F, Hoye A, Daemen J, Tanabe K, Lee CH, Hofma SJ, Sianos G, McFadden E, van der Giessen W, Smits PC, de Feyter PJ, van Domburg RT, Serruys PW. Very long sirolimus-eluting stent implantation for de novo coronary lesions. Am J Cardiol 2004;93(7):826-9.

8. Grube E, Buellesfeld L. BioMatrix Biolimus A9-eluting coronary stent: a next-generation drug-eluting stent for coronary artery disease. Expert Rev Med Devices 2006;3(6):731-41.

9. Windecker S, Serruys PW, Wandel S, Buszman P, Trznadel S, Linke A, Lenk K, Ischinger T, Klauss V, Eberli F, Corti R, Wijns W, Morice MC, di Mario C, Davies S, van Geuns RJ, Eerdmans P, van Es GA, Meier B, Jüni P.
Biolimus-eluting stent with biodegradable polymer versus sirolimus-eluting stent with durable polymer for coronary revascularisation (LEADERS): a randomised non-inferiority trial. Lancet 2008;372(9644):1163-73.

10. Mauri L, Hsieh WH, Massaro JM, Ho KK, D'Agostino R, Cutlip DE. Stent thrombosis in randomized clinical trials of drug-eluting stents. $N$ Engl J Med 2007;356(10):1020-9.

11. Togni M, Eber S, Widmer J, Billinger M, Wenaweser $\mathrm{P}$, Cook S, Vogel R, Seiler C, Eberli FR, Maier W, Corti R, Roffi M, Lüscher TF, Garachemani A, Hess OM, Wandel S, Meier B, Jüni P, Windecker S. Impact of vessel size on outcome after implantation of sirolimus-eluting and paclitaxel-eluting stents: a subgroup analysis of the SIRTAX trial. J Am Coll Cardiol 2007;50(12):1123-31.

12. Windecker $S$, Remondino A, Eberli FR, Jüni $P$, Räber $L$, Wenaweser $P$, Togni M, Billinger M, Tüller D, Seiler C, Roffi M, Corti R, Sütsch G, Maier W, Lüscher T, Hess OM, Egger M, Meier B. Sirolimus-eluting and paclitaxeleluting stents for coronary revascularization. N Engl J Med 2005; 353(7):653-62.

13. Lemos PA, Serruys PW, van Domburg RT, Saia F, Arampatzis CA, Hoye A, Degertekin M, Tanabe K, Daemen J, Liu TK, McFadden E, Sianos G, Hofma SH, Smits PC, van der Giessen WJ, de Feyter PJ. Unrestricted utilization of sirolimus-eluting stents compared with conventional bare stent implantation in the "real world": the Rapamycin-Eluting Stent Evaluated At Rotterdam Cardiology Hospital (RESEARCH) registry. Circulation 2004;109(2):190-5.

14. Lemos PA, Saia F, Ligthart JM, Arampatzis CA, Sianos G, Tanabe K, Hoye A, Degertekin M, Daemen J, McFadden E, Hofma S, Smits PC, de Feyter P, van der Giessen WJ, van Domburg RT, Serruys PW. Coronary restenosis after sirolimus-eluting stent implantation: morphological description and mechanistic analysis from a consecutive series of cases. Circulation 2003;108(3):257-60.

15. Lee CW, Park DW, Lee BK, Kim YH, Hong MK, Kim JJ, Park SW, Park SJ. Predictors of restenosis after placement of drug-eluting stents in one or more coronary arteries. Am J Cardiol 2006;97(4):506-11.

16. Kastrati A, Dibra A, Mehilli J, Mayer S, Pinieck S, Pache J, Dirschinger J, Schömig A. Predictive factors of restenosis after coronary implantation of sirolimus- or paclitaxel-eluting stents. Circulation 2006;113(19):2293-300.

\section{Excerpt from the Reviewers}

Since this is a sub-study, the authors should clearly define what presentation of these results add over and above the results of the main analysis. Slicing and dicing the data has led to some particularly small group comparisons, particularly when it comes to the angiographic follow-up data. The study is under-powered, and therefore some of the results could be explained by play of chance. 